\title{
Intrathecal bupivacaine for head and neck pain
}

\author{
This article was published in the following Dove Press journal: \\ Local and Regional Anesthesia \\ 9 October 2010 \\ Number of times this article has been viewed
}

\author{
Shawn A Belverud \\ Alon Y Mogilner \\ Michael Schulder \\ North Shore University Hospital \\ Department of Neurosurgery, Harvey \\ Cushing Institute for Neuroscience, \\ Manhasset, NY, USA
}

\begin{abstract}
Direct central nervous system (CNS) analgesic delivery is a useful option when more traditional means of dealing with chronic pain fail. Solutions containing local anesthetic have been effective in certain disease states, particularly in patients suffering from intractable head and neck pain. This review discusses historical aspects of CNS drug delivery and the role of intrathecal bupivacaine-containing solutions in refractory head and neck pain patients.

Keywords: chronic pain, analgesics, anesthetic, bupivacaine, head, neck

\section{Introduction}

Direct drug delivery to the neural axis is an effective treatment for primary disorders of the central nervous system (CNS), as well as for a growing number of systemic conditions, when other means have failed or resulted in intolerable side effects. ${ }^{1,2}$ Neuromodulation in chronic pain patients traditionally has involved opiate-based drugs; however, the treatment of certain pain states may be improved with a mixture of opiates and local anesthetics or infused local anesthetics alone. This review discusses the role of intrathecal (IT) infusion of local anesthetic, specifically bupivacaine, in patients suffering from chronic, intractable head and neck pain.
\end{abstract}

\section{Intrathecal pain control}

As a group, chronic pain patients may challenge even the most adept physician. Due to the high number of chronic pain generators and the disparate emotional and physical responses that are manifest in patients, therapeutic options have evolved to allow for individualized treatments. ${ }^{3,4}$ To add further to the complexities, significant alterations in neural circuitry lead to changing medication requirements; this, coupled with ever increasing tolerance and systemic side effects, makes the management of chronic pain quite dynamic. When conventional means of effective pain management fail to treat patients effectively or side effects progress to bar further use, an alternative mode of analgesic delivery should be sought.

Direct CNS delivery of analgesics offers multiple advantages: avoidance of the blood-brain barrier, bypassing systemic metabolism that may yield adverse drug interactions, use of fractionated doses of medication, the ability to achieve constant level of active drug, and immediate access to receptors. All of these make IT delivery especially attractive. The concept of IT delivery is hardly novel. August Bier first described 'cocainization of the spinal cord' in 1898 and phenol was used in the management of malignant pain in the 1960s. ${ }^{5}$ CNS opioid receptors were found in
Correspondence: Michael Schulder North Shore University Hospital, 9 Tower, 300 Community Drive, Manhasset, NY I 1030, USA Email schulder@nshs.edu 
the early 1970s, and IT morphine injections, first in animals ${ }^{6}$ and then in humans, ${ }^{7}$ each displayed safety and effective analgesia. While IT opioids at first were used primarily to treat patients with cancer-related pain, they are now used in the treatment of a wide range of malignant and nonmalignant causes of primarily nociceptive pain. Current US Food and Drug Administration (FDA)-approved drugs for IT use in chronic pain patients are morphine sulfate and ziconotide.

\section{Intrathecal bupivacaine}

Epidural bupivacaine hydrochloride, a local anesthetic of the amide group, has proved to be an effective epidural analgesic in obstetrical patients as well in those suffering from malignant and nonmalignant spine pain. ${ }^{8}$ The success of the FDA-approved IT analgesics has fostered a search for other primary IT medications and for other drugs that could augment the effects of morphine via co-administration. Combinations of opioids and local anesthetic are now used extensively in both malignant and a growing proportion of nononcogenic pain patients. ${ }^{9-11}$

Toxicology studies have demonstrated the safety of chronic IT bupivacaine infusions in numerous models including the dog, rabbit, and cat. ${ }^{12-14}$ Furthermore, a 1989 study by Burm displayed only mild neurologic toxicity with IT bupivacaine concentrations 100 times higher than those necessary for clinical effect. ${ }^{15}$ Animal studies with local anesthetics and opioids have demonstrated a synergistic potentiation of antinociceptive effects. ${ }^{16}$ The available safety data with chronic infusion in humans has proven favorable. In addition, postmortem spinal tissue histology in terminal cancer patients did not show neurotoxicity after the administration of chronic IT morphine sulfate in combination with bupivacaine. ${ }^{17,18}$ However, there have been no randomized control studies looking at the effectiveness or safety of IT bupivacaine administration.

As progress has been made in the use of IT opioids with or without local anesthetic for those suffering from low back pain, the search for effective treatment of patients with refractory head and neck pain has proved much more difficult. Studies have described the use of both anesthetic and neurosurgical means, including electrical stimulation of both brain and spine, ${ }^{19} \mathrm{C} 2-5$ posterior root rhizotomies, $\mathrm{C} 2$ cordotomy, stereotactic medial thalamotomy, ${ }^{20}$ intraventricular morphine, ${ }^{21}$ and the intracisternal administration of destructive agents ${ }^{22}$ and analgesics. ${ }^{23}$ Results have been limited secondary to ineffective analgesia and/or unacceptable side effects. High cervical IT (HCIT)/intracisternal bupivacaine, however, has a limited but expanding number of single case series reports supporting its effectiveness in treating patients with refractory head and neck pain.

In 1994, Crul et al reported on two patients with end-stage oral cancer refractory to conventional pain management. ${ }^{24}$ Each patient had a catheter placed from a lateral C1-2 approach into the cisterna magna followed by HCIT morphine infusion. In both patients, the IT morphine failed to significantly assuage their pain and bupivacaine was added to the solution. The addition allowed the first patient the ability to sleep and significantly reduced the paroxysmal pain as well as the baseline discomfort. The patient was able to be released from the hospital and died 12 days later from her cancer. The second patient also had significantly better pain control after the addition of HCIT bupivacaine. In this case, transient increased disequilibrium was eliminated with titration of the bupivacaine dose from 9.6 to $6.6 \mathrm{mg} / 24 \mathrm{hr}$. After 6 months, the patient reported near complete pain relief (Visual analog scale [VAS], 1-2) as well as undisturbed sleep. No complications were reported in either case.

In 2002, Baker et al reported on six patients who received HCIT bupivacaine with diamorphine \pm clonidine and/or baclofen in a palliative setting for a mean of 67 (13-87) days via an external reservoir system. ${ }^{25}$ All patients had severe neuropathic pain secondary to tumor invasion, two of which included a trigeminal distribution. In all cases, pain was reduced significantly, allowing for reduction in systematic opioids and/or adjuvant analgesic doses. No major complications were reported (one patient reported arm weakness/numbness but preferred that to the pain), and all side effects were mitigated by changes in medication dosages (hypotension was reduced by decreasing clonidine infusion). No degree of respiratory depression occurred secondary to the HCIT local anesthetic solution. The mean dose of bupivacaine in the combination solution was $46 \mathrm{mg} / 24 \mathrm{hr}$ (20-75).

In 1996, Appelgren et al reported on 13 patients afflicted with head and/or neck pain (four from nonmalignant causes, nine malignant) all treated with continuous HCIT bupivacaine infusion. ${ }^{26}$ The same group recently reported an update of their experience spanning from 1990-2005. ${ }^{27}$ The 40 neuropathic or mixed pain patients had a median age of 67 (27-84), 15 were noncancer patients, and the median duration of pain was 1.8 years ( 1 month-18 years). Inclusion criteria included the following: (1) pain dominating patient's life; (2) traditional analgesia had failed; and (3) unacceptable side effects. Depression, senility, and severe physical conditions were not considered contraindications; moribund patients and those with overt psychoses were excluded. 
Catheters were placed from an interlaminar approach (35: C7-T4 and 4: T4-9), save one direct occipital catheter. All but three catheter tips were placed into the cisterna magna or at the $\mathrm{C} 1 / \mathrm{C} 2$ theca. The others remained at $\mathrm{C} 3$ secondary to difficulty in navigation. All catheters, once in final position, were subcutaneously tunneled to the subclavicular space and a $1 \mathrm{~mL}$ bolus (bupivacaine $5 \mathrm{mg} / \mathrm{mL}$ ) was given and then connected to a filter and external reservoir. Once connected, a bupivacaine infusion $(5 \mathrm{mg} / \mathrm{mL})$ was commenced at $0.1-0.2 \mathrm{mg} / \mathrm{hr}$, using a patient-controlled bolus dose of $0.1-0.2 \mathrm{mg}$ with a 15 -minute lockout, titrated to patient needs.

The study reported on 2570 HCIT treatment days, 1567 of which occurred at the patient's home. Most patients (27/40) experienced complete pain relief, and partial pain relief was attained in four (median change in VAS was from 10 to 2). Improvement in sleep quality was identified in half of the patients, and a majority reported improvement in their ability to ambulate. The mean daily doses ranged from $10 \mathrm{mg}$ to $59 \mathrm{mg}$ amongst the disparate groups; however, individual differences were quite small. Opioid reduction varied significantly, but those individuals who responded to HCIT saw significant reductions in systematic analgesics.

The most common complication in the series was facial, cervical, or extremity paresthesias. These and other mild side effects could be effectively treated adjusting the infusion rate. No patient had respiratory sequelae or dysphagia. No mortality or significant neurological damage was attributed to the study. Two exit-site infections were treated with removal of the catheter, and the chief reason for removal of the system was death.

\section{Discussion}

The key to success in any procedure is appropriate patient selection; this is perhaps the most critical aspect of neuromodulation. This is often done best with a multidisciplinary team that considers the needs of each individual. The patient's immediate support group (family and other loved ones) should be involved, not only to assess the appropriateness of the intervention, but to also educate them as to what to expect after the procedure is completed. Once there is agreement to move forward, there are some technical considerations specific to bupivacaine that should be considered.

The techniques involved with high cervical catheter placement have been previously described. ${ }^{24,28}$ It is of paramount importance to localize the catheter tip at the level that corresponds to the patient's pain. ${ }^{29}$ Bupivacaine's local anesthetic effects are quite localized, and if the catheter tip is not to the correct level, the result could be diminished pain relief.
Beyond the side effects heretofore discussed, there are others reported in the literature related specifically to IT bupivacaine administration, including reports of aseptic meningitis. ${ }^{30-32}$ If dosing errors do occur and superfluous drug is introduced intrathecally, cerebrospinal fluid lavage with normal saline or lactated Ringer's solution has been successful in rapid elimination of the local anesthetic. ${ }^{33}$ Nearly all other complications can be mitigated or eliminated with titration of IT bupivacaine dosing.

\section{Conclusion}

Though not often used, IT bupivacaine solutions appear to offer properly selected head and neck pain patients a means of increased pain relief when other options have failed. As more authors report their results, we hope to attain a better understanding of the indications, techniques, and complications related to this treatment modality.

\section{Disclosure}

The authors report no conflicts of interest in this work.

\section{References}

1. Belverud S, Mogilner A, Schulder M. Intrathecal pumps. Neurotherapeutics. 2008;5(1):114-122.

2. Belverud S, Mogilner A, Schulder M. Intrathecal drug delivery by implanted pumps. In: Jain KK, editor. Drug Delivery to the Central Nervous System. New York, NY: Springer; 2010:137-154.

3. Arnstein P, Caudill M, Mandle CL, et al. Self efficacy as a mediator of the relationship between pain intensity, disability and depression in chronic pain patients. Pain. 1999;80:483-491.

4. Schmitz U, Saile H. Nilges P. Coping with chronic pain: flexible goal adjustment as an interactive buffer against pain-related distress. Pain. 1996;67:41-51.

5. Brill S, Gurman G, Fisher A. A history of neuraxial administrationof local analgesics and opioids. Eur J Anaesthesiol. 2003;20:682-689.

6. Yaksh TL, Rudy TA. Studies on the direct spinal action of narcotics in the production of analgesia in the rat. J Pharmacol Exp Ther. 1977; 202(2):411-428.

7. Wang JK, Nauss L, Thomas JE. Pain relief by intrathecally applied morphine in man. Anesthesiology. 1979;50(2):149-151.

8. Krames E. Intraspinal opioid therapy for chronic nonmalignant pain: current practice and clinical guidelines. J Pain Sympt Manag. 1996, $11: 333-352$.

9. Deer TR, Caraway D, Kim CK, Dempsey CD, et al. Clinical experience with intrathecal bupivacaine in combination with opioid for the treatment of chronic pain related to failed back surgery syndrome and metastatic cancer pain of the spine. Spine J. 2002;2:274-278.

10. Nitescu P, Dahm P, Appelgren L, Curelaru I. Continuous infusion of opioid and bupivacaine by externalized intrathecal catheters in long-term treatment of "refractory" nonmalignant pain. Clin J Pain. 1998; 14:17-28.

11. Deer T, Krames E, Hassenbusch SJ, et al. Polyanalgesic consensus conference 2007: Recommendations for the management of the pain by intrathecal (intraspinal) drug delivery: report of an interdisciplinary expert panel. Neuromodulation. 2007;10(4):300-328.

12. Li DF, Bahar M, Cole G, Rosen M. Neurological toxicity of the subarachnoid infusion of bupivacaine, lignocaine or 2-chloroprocaine in the rat. Br J Anaesth. 1985;57:424-429. 
13. Kroin JS, McCarthy R, Penn RD, et al. The effect of chronic subarachnoid bupivacaine infusion in dogs. Anesthesiology. 1987;66:737-742.

14. Ready L, Plumer M, Fink B, Sumi S. Intrathecal local anesthetic toxicity in rabbits. Anesthesiology. 1983;59:A187.

15. Burm A. Clinical pharmacokinetics of epidural and spinal anesthesia. Clin Pharmacokinet. 1989;16:283-311.

16. Saito Y, Kaneko M, Kirihara Y, et al. Interaction of intrathecally infused morphine and lidocaine in rats (Part 1): synergistic antinociceptive effects. Anesthesiology. 1998;89:1455-1463.

17. Sjoberg M, Appelgren L, Einarsson S, et al. Long-term intrathecalmorphine and bupivacaine in "refractory" cancer pain. I. Results from the first series of 52 patients. Acta Anaesthesiol Scand. 1991;35:30-43.

18. Nitescu P, Dahm P, Appelgren L, Curelaru I. Continuous infusion of opioid and bupivacaine by externalized intrathecal catheters in longterm treatment of "refractory" non-malignant pain. Clin J Pain. 1998; $14(1) ; 17-28$.

19. Freidberg S. The neurosurgeon's approach to pain. In: Aronoff GM, editor. Evaluation and Treatment of Chronic Pain. Baltimore, MD: Williams \& Wilkins; 1992:229-237.

20. Jannetta PJ, Loeser JD, Sweet WH, Ojemann GA. Operations on the brain and brainstem for chronic pain. In: Bonica J, editor. The Management of Pain. Philadelphia, PA: Lea and Febiger; 1990:2082-2104.

21. Lobato RD, Madrid JL, Fatela LV, Rivas JJ, et al. Intraventricular morphine for control of pain in terminal cancer patients. J Neurosurg. 1983;59:627-633.

22. Bortoluzzi M, Marini G. Phenol injection into cisterna magna for relief of advanced intractable cancer pain in the faciocephalic area. J Neurosurg Sci. 1986;30:167-176.

23. Ascoli Marchetti V, Amodei C, Spaziani S, Rabuffi S, Sabato AF. [Patient controlled analgesia (PCA) with morphine in the cisterna magna for treatment of oncologic cerebro-cervico-brachial pain]. Minerva Anestesiol. 1990;56:1135-1139.
24. Crul BJ, van Dongen R, Snijdelar DG, Rutten EH. Longterm continuous intrathecal administration and bupivacaine at the upper cervical level: access by lateral C1-C2 approach. Anesth Analg. 1994;79:594-597.

25. Baker L, Balls J, Regnard C, Pridie A. Cervical intrathecal analgesia for head and neck/upper limb cancer pain: six case reports. Palliat Med. 2007;21:543-545.

26. Appelgren L, Janson M, Nitescu P, Curelaru L. Continuous intracisternal and high cervical intrathecal bupivacaine analgesia in refractory head and neck pain. Anesthesiology. 1996;84:256-272.

27. Lundborg C, Dahm P, Nitescu P, Biber B. High intrathecal bupivacaine for severe pain in the head and neck. Acta Anaesthesiol Scand. 2009; 53(7):908-913.

28. Nitescu P, Appelgren L, Hultman E, Linder LE, Sjöberg M, Curelaru I. Long-term, open catheterization of the spinal subarachnoid space for continuous infusion of narcotic and bupivacaine in patients with "refractory" cancer pain: a technique of catheterization and its problems and complications. Clin J Pain. 1991;7(2):143-161.

29. Greene N. Uptake and elimination of local anesthetics during spinal anesthesia. Anesth Analg. 1983;62:1013-1024.

30. Tateno F, Sakakibara R, Kishi M, Ogawa E. Bupivacaine-induced chemical meningitis. J Neurol. 2010;257(8):1327-1329.

31. Mekonnen D, Bane A. Meningitis complicated with sinus venous thrombosis and intracranial hemorrhage in a patient who received bupivacaine spinal anesthesia. Ethiop Med J. 2008;46(3):277-280.

32. Besocke AG, Santamarina R, Romano LM, Femminini RA. Meningitis aséptica inducida por bupivacaína. Neurologia. 2007;22(8):551-552.

33. Tsui BC, Malherbe S, Koller J, Aronyk K. Reversal of an unintentional spinal anesthetic by cerebrospinal lavage. Anesth Analg. 2004;98(2):434-436.
Local and Regional Anesthesia

\section{Publish your work in this journal}

Local and Regional Anesthesia is an international, peer-reviewed, open access journal publishing on the development, pharmacology, delivery and targeting and clinical use of local and regional anesthetics and analgesics. The journal welcomes submitted papers covering original research, basic science, clinical studies, reviews \& evaluations,

\section{Dovepress}

guidelines, expert opinion and commentary, case reports and extended reports. The manuscript management system is completely online and includes a very quick and fair peer-review system, which is all easy to use. Visit http://www.dovepress.com/testimonials.php to read real quotes from published authors. 